\title{
Development of a species-specific polymerase chain reaction assay for Gardnerella vaginalis
}

\author{
Alex van Belkum, ${ }^{1 *}$ Ankie Koeken, ${ }^{2}$ Peter Vandamme, ${ }^{3,4}$ Marjan van Esbroeck, ${ }^{3}$ \\ Herman Goossens, ${ }^{3}$ Jolanda Koopmans, ${ }^{5}$ Johan Kuijpers, ${ }^{5}$ Enevold Falsen ${ }^{6}$ and \\ Wim Quint ${ }^{2}$ \\ 'University Hospital Dijkzigt, Department of Bacteriology, Dr. Molewaterplein 40, 3015 \\ GD Rotterdam, The Netherlands; ${ }^{2}$ Diagnostic Center SSDZ, Department of Molecular \\ Biology, P.O. Box 5010, 2600 GA Delft, The Netherlands; ${ }^{3}$ University Hospital Antwerp, \\ Department of Medical Microbiology, Antwerp, Belgium; ${ }^{4}$ University of Ghent, \\ Department of Microbiology, Ghent, Belgium; ${ }^{5}$ Reinier de Graaf Hospital, Department of \\ Gynaecology, Reinier de Graafweg 11, P.O. Box 5010, 2600 GA Delft, The Netherlands; \\ ${ }^{6}$ Department of Clinical Bacteriology, University of Göteborg, S-41346 Göteborg, \\ Sweden
}

(Received 8 September 1994, Accepted 31 January 1995)

\begin{abstract}
The nucleotide sequence of the region between the $16 \mathrm{~S}$ and $23 \mathrm{~S}$ rRNA genes of the facultative anaerobic bacterium Gardnerella vaginalis has been determined, together with the $5^{\prime}$ proximal 500 nucleotides of the 23S rRNA gene. Regions suited for the development of specific, probeconfirmable polymerase chain reaction (PCR) assays were selected. PCR assays were evaluated with respect to sensitivity and specificity, the latter in comparison with a number of $G$. vaginalis reference strains and closely related species like Bifidobacterium spp. In an initial diagnostic study it appeared that the PCR test detected G. vaginalis in $40 \%$ of women irrespective of their clinical status. Ten out of 11 patients suffering from bacterial vaginosis as defined on the basis of clinical parameters were carrying $G$. vaginalis.
\end{abstract}

KEYWORDS: Gardnerella vaginalis, polymerase chain reaction, internal transcribed spacer region.

\section{INTRODUCTION}

The three main categories of vaginitis are caused by Trichomonas vaginalis, yeast or bacteria.' Bacterial vaginosis (BV) by itself accounts for up to $50 \%$ of all patient cases. ${ }^{2}$ It became apparent that a large number of organisms also present in the healthy vaginal flora can become predominant during periods of $\mathrm{BV}$. Among these are species like Veillonella parvula, ${ }^{3}$ Mycoplasma hominis, ${ }^{4}$ Peptostreptococcus spp., ${ }^{5} \mathrm{Mo}-$ biluncus spp. ${ }^{6}$ and Gardnerella vaginalis. ${ }^{7}$ Most of these organisms have also been implicated as potential causes of $B V$ sequelae like pelvic inflammatory disease, ${ }^{8}$ postpartum endometritis ${ }^{9}$ and urinary tract infection. $^{10}$

Gardnerella vaginalis is an interesting member of the array of BV-related organisms. An extensive number of microbiological, biochemical and molecular studies has been performed in order to gain insight in the organisms' classification and life cycle.,11 $G$.

* Author to whom correspondence should be sent. 
vaginalis still is the sole species in the genus and immunochemical detection and identification was described by several authors. ${ }^{12,13} \mathrm{G}$. vaginalis-specific DNA segments appeared to be useful for species determination ${ }^{14,15}$ and a DNA probe specific for $G$. vaginalis rRNA was developed. ${ }^{16}$

In this study we developed a $G$. vaginalis-specific polymerase chain reaction (PCR), which could be used for species identification and detection. The nucleotide sequence of the internal transcribed spacer region as present between $16 \mathrm{~S}$ and $23 \mathrm{~S}$ rRNA genes and the $5^{\prime}$ part of the $23 \mathrm{~S}$ rRNA gene were determined. Based on these sequences several PCR assays were designed and evaluated.

\section{MATERIALS AND METHODS}

\section{Bacterial strains and DNA purification}

Table 1 surveys the bacterial strains that were obtained from clinical practice or the ATCC, CCUG or LMG culture collections and were grown on agar-based media before DNA extraction. Two subcultures of the type strain of G. vaginalis (CCUG $3717^{\top}$ and ATCC $14018^{\top}$ ) were included. Reference strains were characterized by means of cellular fatty acid analysis ${ }^{17}$ and the rapid ID32 strep Microtest (BioMerieux, France) (Falsen, van Esbroeck and Goossens, unpublished data). G. vaginalis $2887 / 10$ through $9895 / 24$ are clinical isolates (see Table 1). These isolates were characterised on the basis of colony morphology and a negative catalase test. Special attention was given to Bifidobacterium species since $16 \mathrm{~S}$ rRNA sequence analysis revealed a close relatedness between Bifidobacteria and G. vaginalis. ${ }^{18}$ Cells were harvested in phosphate buffered saline (PBS) $\mathrm{pH} 7.0$ and DNA was isolated and purified by subsequent proteinase $\mathrm{K}$ digestion $\left(1 \mathrm{mg} \mathrm{ml}^{-1}\right.$ proteinase $\mathrm{K}$ in $10 \mathrm{mM}$ Tris$\mathrm{HCl} \mathrm{pH} \mathrm{8.0,} 1 \mathrm{~mm}$ EDTA, $1 \%$ SDS for $1 \mathrm{~h}$ at $37^{\circ} \mathrm{C}$ ) and phenol extractions. After the extractions DNA was precipitated using ethanol and the resulting pellet was dissolved in distilled water. The DNA concentrations of the final solutions was determined spectrophotometrically and was adjusted to $10 \mathrm{ng} \mu \mathrm{l}^{-1}$. DNA solutions were stored at $-20^{\circ} \mathrm{C}$.

\section{PCR amplification}

PCRs were performed in Biomed model 60 thermocyclers. The reaction mixtures $(100 \mu \mathrm{l})$ consisted of $60 \mathrm{~mm}$ Tris- $\mathrm{HCl} \mathrm{pH} 9.0,2.5 \mathrm{mM} \mathrm{MgCl}, 50 \mathrm{mM} \mathrm{KCl}$, $0.01 \%$ Triton $X-100,0.2 \mathrm{mM}$ desoxyribonucleotide triphosphates, 0.25 $U$ Tth DNA polymerase (Sphaero
$\mathrm{Q}$, Leiden, The Netherlands) and $50 \mathrm{pmol}$ of both sense and antisense primers. The PCR programme consisted of a $2-\mathrm{min}$ predenaturation step at $94^{\circ} \mathrm{C}$. Cycling involved 40 times $1 \mathrm{~min} 94^{\circ} \mathrm{C}, 1 \mathrm{~min} 50^{\circ} \mathrm{C}$ and $1 \mathrm{~min} 74^{\circ} \mathrm{C}$. Reaction products were analysed by electrophoresis through 1-3\% agarose gels in $40 \mathrm{~mm}$ Tris-acetate $\mathrm{pH} 7 \cdot 8,2 \mathrm{~mm}$ EDTA, followed by ethidium-bromide staining and Polaroid photography.

\section{Amplification and sequence determination of the ribosomal intergenic spacer region}

In order to determine the internal transcribed spacer (ITS) DNA sequence for $G$. vaginalis, DNA from $G$. vaginalis ATCC $14018^{\top}$ was PCR amplified using $16 \mathrm{~S}$ and $23 \mathrm{~S}$ ribosomal consensus primers (primers \#3 and the complement of $\# 5^{19}$ ). One of the primers was equipped with a biotin moiety at its $5^{\prime}$ end. After PCR, the biotinylated DNA fragment (approximately $870 \mathrm{bp}$ in length) was bound to Streptavidin-coated magnetic beads (Dynabeads M280, Dynal AS, Oslo, Norway). These beads were subsequently treated with alkali $(0.2 \mathrm{M} \mathrm{NaOH})$ and the water phase was neutralized by addition of equimolar amounts of hydrochloric acid and 1/10 volume $1 \mathrm{M}$ Tris- $\mathrm{HCl} \mathrm{pH} 8 \cdot 0$. Both the DNA coupled to and eluted from the beads was subjected to manual dideoxy sequencing according to Sanger (T7 sequencing kit, Pharmacia, the Netherlands). ${ }^{35}$ S-labelled dATP (Amersham, UK) was used for radioactive labelling of the reaction products. Sequence determination was performed by use of the PCR primers and sequencing primers $A$ through $F$ (Table 2).

\section{Selection and evaluation of $G$. vaginalis specific PCR primers and probes}

The $G$. vaginalis ITS sequence was compared to similar sequences as determined for Streptococcus pneumoniae, Anacystis nidulans, Escherichia coli, Rhodobacter sphaeroides, Mycobacterium leprae and Streptomyces griseus using PC gene software and the Genbank sequence depository (Genbank, National Center for Biotechnology Information, Bethesda, USA). Comparisons among this phylogenetically diverse set of prokaryotes led to the determination of various hypervariable DNA sequence loci. Speciesspecific oligonucleotides ( $D$ and $G$ through $K$ ) deduced from these regions are indicated in Table 2. Various PCR tests, enabled by the selection of the most variable domains, were performed. The bacteria mentioned in Table 1 were used as a reference panel. 
Table 1. Survey of organisms used for the validation of the $G$. vaginalis specific PCR tests

\begin{tabular}{|c|c|c|c|c|c|c|c|c|c|}
\hline \multirow[t]{2}{*}{ Bacterial species } & & & \multirow{2}{*}{$\begin{array}{l}\text { PCR } \\
\text { probe }\end{array}$} & \multirow{2}{*}{$\begin{array}{c}\mathrm{G} / \mathrm{J} \\
\mathrm{H}\end{array}$} & \multicolumn{2}{|c|}{$H / K$} & \multicolumn{3}{|c|}{$G / K$} \\
\hline & & & & & J & $\mathrm{D}$ & $\mathrm{H}$ & $J$ & $\mathrm{D}$ \\
\hline Gardnerella vaginalis & CCUG & $3717^{\top}$ & & + & + & + & + & + & + \\
\hline Gardnerella vaginalis & CCUG & 3990 & & + & + & + & + & + & + \\
\hline Gardnerella vaginalis & CCUG & 4123 & & + & + & + & + & + & + \\
\hline Gardnerella vaginalis & CCUG & 7921 & & + & + & + & + & + & + \\
\hline Gardnerella vaginalis & CCUG & $11278 \mathrm{~A}$ & & + & + & + & + & + & + \\
\hline Gardnerella vaginalis & CCUG & 28963 & & + & + & + & + & + & + \\
\hline Gardnerella vaginalis & CCUG & 30587 & & + & + & + & + & + & + \\
\hline Gardnerella vaginalis & CCUG & 30841 & & + & + & + & + & + & + \\
\hline Gardnerella vaginalis & CCUG & 7154 & & + & + & + & + & + & + \\
\hline Gardnerella vaginalis & CCUG & 7712 & & + & + & + & + & + & + \\
\hline Gardnerella vaginalis & ATCC & $14018^{\top}$ & & + & + & + & + & + & + \\
\hline Gardnerella vaginalis & & $2887 / 10$ & & + & + & + & + & + & + \\
\hline Gardnerella vaginalis & & $3064 / 17$ & & \pm & \pm & + & + & + & + \\
\hline Gardnerella vaginalis & & $5457 / 19$ & & $\bar{t}$ & $\bar{t}$ & + & + & + & + \\
\hline Gardnerella vaginalis & & $5391 / 18$ & & + & + & + & + & + & + \\
\hline Gardnerella vaginalis & & $4841 / 9$ & & + & + & + & + & + & + \\
\hline Gardnerella vaginalis & & $9895 / 24$ & & + & + & + & + & + & + \\
\hline Bifidobacterium brevis & LMG & 13208 & & - & - & - & - & - & - \\
\hline Bifidobacterium longum & $\mathrm{LMG}$ & 13207 & & - & - & - & - & - & - \\
\hline Bifidobacterium magnum & LMG & 11590 & & - & - & - & - & - & - \\
\hline Bifidobacterium bifidum & LMG & •13209 & & - & - & - & - & - & \pm \\
\hline Bifidobacterium infantis & LMG & 13203 & & - & - & - & - & - & - \\
\hline Lactobacillus acidophilus & & $01719 / 8$ & & - & - & - & - & - & - \\
\hline Lactobacillus acidophilus & & 01834 & & - & - & - & \pm & + & + \\
\hline Lactobacillus acidophilus & & 01893 & & - & - & - & \pm & + & + \\
\hline Lactobacillus acidophilus & & 02028 & & - & - & - & - & - & - \\
\hline Lactobacillus acidophilus & & 01997 & & - & - & - & \pm & - & - \\
\hline Lactobacillus acidophilus & & 01919 & & - & - & - & $\overline{ \pm}$ & + & + \\
\hline Lactobacillus acidophilus & & $2604 / 5$ & & - & - & - & $\overline{-}$ & - & - \\
\hline Lactobacillus acidophilus & & $2604 / 8$ & & - & - & - & - & - & - \\
\hline Lactobacillus acidophilus & & $3313 / 16$ & & - & - & - & - & - & - \\
\hline Lactobacillus acidophilus & & $5656 / 19$ & & - & - & - & - & - & - \\
\hline Mycoplasma hominis & & & & - & - & - & - & - & - \\
\hline Escherichia coli & & & & - & - & - & - & - & - \\
\hline Chlamydia trachomatis & & & & - & - & - & - & - & - \\
\hline Bacillus subtilis & & & & - & - & - & - & - & - \\
\hline Listeria monocytogenes & & & & - & - & - & - & - & - \\
\hline Streptococcus agalactiae & & & & - & - & - & - & - & - \\
\hline Shigella flexneri & & & & - & - & - & - & - & - \\
\hline
\end{tabular}

Gardnerella vaginalis $2887 / 10$ to Lactobacillus acidophilus $5658 / 19$ are clinical isolates. For the following organisms the HK PCR in combination with DNA probe D was performed: Clostridium perfringens, Helicobacter pylori, Enterobacter agglomerans, Campylobacter jejuni, Enterabacter cloacae, Staphylococcus saprophyticus, Klebsiella pneumoniae, Pseudomonas cepacia, Listeria monocytogenes, Citrobacter freundii, Proteus vulgaris, Pseudomonas aeruginosa, Bacillus fragilis, Salmonella serovar godesberg, Haemophilus influenzae, Salmonella serovar senftenberg, Moraxella catarrhalis, Shigella flexneri, Staphylococcus aureus, Bordetella pertussis, Streptococcus agalactiae, Enterococcus faecalis, Cryptococcus neoformans, Staphylococcus epidermidis and Candida albicans.

The PCR conditions were as described above. Amplified DNA was analysed by electrophoresis and after staining with ethidium bromide and Polaroid photography, gels were Southern blotted onto Hybond $\mathrm{N}^{+}$nylon filters. Subsequently, the amplified DNA was identified by hybridization with 5 -end-lapbelled probes. Labelling and hybridization were performed by standard methods. ${ }^{20}$ Autoradiography was executed for $3-16 \mathrm{~h}$ at $-70^{\circ} \mathrm{C}$ using Kodak X-omat AR films.

\section{Diagnostic application of the $G$. vaginalis PCR test}

Twelve CCUG strains of $G$. vaginalis and a single $S$. acidominimus strain of which six displayed abberant biochemical profiles or fatty acid profiles were analysed blindly by the PCR in order to reconfirm the species nature (see Table 3). PCR was performed using primers $\mathrm{H}$ and $\mathrm{K}$ and amplified DNA was probed with primer $\mathrm{D}$. 
Table 2. Survey of oligonucleotides used for sequencing and amplification of the $G$. vaginalis internal transcribed spacer region

\begin{tabular}{|c|c|c|c|c|}
\hline Primer code & Aim & Polarity & Position & Nucleotide sequence \\
\hline A & $\mathrm{S}$ & + & $512-531(23 S)$ & GGAGACCCGGCCACTGTTAT \\
\hline B & $\mathrm{S}$ & - & $468-449(235)$ & GAGGCATATCGCAGCCCGTC \\
\hline C & $\mathrm{S}$ & - & $301-282$ (ITS) & GGAGCCGGTTGAAATTGATA \\
\hline $\mathrm{D}$ & $S / P$ & - & $669-650(23 S)$ & СACCTGACGGTTATCACACG \\
\hline$E$ & $\mathrm{~S}$ & - & $423-404(23 S)$ & AAGGGCATCCAACCAATACGC \\
\hline $\mathrm{F}$ & $\mathrm{S}$ & + & $404-423(23 S)$ & GCGTATTGGTTGGATGCCTT \\
\hline G & $P$ & + & 282-301 (ITS) & TATCAATITCAACCGGCTCC \\
\hline $\mathrm{H}$ & $\mathrm{P}$ & + & $381-400(23 S)$ & ПITACTGGTGTATCACTGTA \\
\hline 1 & P & + & $536-552(23 S)$ & GGTACACCACAGTTTTTGTGG \\
\hline J & $\mathbf{P}$ & - & $552-536(23 \mathrm{~S})$ & CCACAAAAACTGTGGTGTACC \\
\hline k & $P$ & - & $714-696(23 S)$ & CCGTCACAGGCTGAACAG \\
\hline
\end{tabular}

The suffix $S$ in the primer number indicates a sequencing primer, $P$ indicates probe or $P C R$ primer. The $G$. vaginalis specific base sequences were deduced by comparisons with other known ITS and 235 sequences and the location of the primers in either the ITS or the $23 \mathrm{~S}$ sequence is indicated between brackets.

Table 3. Comparison of biochemical and fatty acid profiling and PCR mediated strain identification for $G$. vaginalis

\begin{tabular}{lllll}
\hline $\begin{array}{l}\text { code } \\
\text { nr. }\end{array}$ & $\begin{array}{l}\text { CCUG } \\
\text { nr. }\end{array}$ & $\begin{array}{l}\text { fatty } \\
\text { acid }\end{array}$ & $\begin{array}{l}\text { ID32 } \\
\text { strep }\end{array}$ & PCR \\
\hline 1 & 26756 & + & + & - \\
2 & 4121 & + & + & + \\
3 & 26920 & + & + & + \\
4 & 10059 & + & + & + \\
5 & 7132 & - & - & - \\
6 & 26996 & + & + & + \\
7 & 30840 & - & + & + \\
8 & 28963 & + & + & + \\
9 & 26921 & + & - & + \\
10 & 26939 & + & + & + \\
11 & 7751 & + & - & + \\
12 & 27435 & + & - & \pm \\
13 & 11675 & - & - & - \\
\hline
\end{tabular}

Strain 11675 is $S$. acidominimus. PCR has been performed using primer set $\mathrm{H} / \mathrm{K}$ combined with probe $\mathrm{D} .{ }^{\prime}+$ " indicates identity, "-" non-identity with the expected value for $G$. vaginalis.

In order to evaluate the clinical applicability of the $G$. vaginalis test and to establish $G$. vaginalis prevalence in women living in the area around or within Delft (the Netherlands), several groups of females were selected. Cervical smears were collected from 52 females attending the gynaecology department for either cervical cytology screening ( $n=$ 32) or gynaecological problems not related to bacteriological infection $(n=20)$. These patients are considered normal controls, since no apparent growth of G. vaginalis was observed upon cultivation of the cervical smears. No clinical signs of bacterial vaginosis were documented either, thereby corroborating the apparent absence of cultivable $G$. vaginalis. Smears were also obtained from 11 women suffering from clinically confirmed bacterial vaginosis
(BV). Finally, 20 pregnant females were sampled at time of delivery and the body weight of all babies was determined, as was duration of gestation. Smears were obtained using Ayre spatulas which were immersed in culture medium and transported to the lab, where a DNA isolation was carried out. A $100-\mu l$ sample of the smear was incubated with proteinase $\mathrm{K}$ and Triton- $\mathrm{X} 100$ at $37^{\circ} \mathrm{C}$ for $1 \mathrm{~h}$. After $10 \mathrm{~min}$ of boiling, the material could be used as amplification template. ${ }^{20}$ DNA was subjected to two PCRs (G) and HK primer combination) and reaction products were typed by hybridization with DNA probes. All cervical samples displayed normal cytology and no HPV16 or 18 could be detected by PCR. ${ }^{20}$

\section{RESULTS}

\section{Sequence analysis}

The nucleotide sequence of a DNA fragment of $855 \mathrm{bp}$ was determined (Genbank accession number L08167). At the $5^{\prime}$ end, 13 bases of the 165 rRNA gene were present, whereas the $23 \mathrm{~S}$ rRNA sequence started around position 370 . This implies that the genuine-ITS sequence comprised approximately $360 \mathrm{bp}$. Using PC gene software, no tRNA genes could be detected within this region. The results of the sequence comparisons, leading to design of the PCR primers and probes mentioned below are available upon request.

\section{Evaluation of PCR assays}

The selection of $G$. vaginalis-specific oligonucleotides enabled three PCR tests to be performed. Primer G 
could be combined with primer J, making $\mathrm{H}$ the probe of choice. Combining primers $\mathrm{H}$ and $\mathrm{K}$ for PCR makes both primers $\mathrm{J}$ and $\mathrm{D}$ suitable for probe hybridization. With primers $G$ and $K$ in the PCR, primers $\mathrm{H}, \mathrm{J}$ and $D$ turn into suitable probes (see also Table 2). The results of PCR/probing analyses are summarized in Table 1. Although some of the non-Gardnerella organisms displayed DNA amplification using the specific PCR primers, upon hybridization none of these amplimers crosshybridizes with the probe used (see also Figure 1). Only in case of the G/K PCR some falsepositives became apparent. Minor crossreactivity was observed towards Bifidobacterium bifidum, but major specificity problems were encountered when Lactobacillus acidophilus strains were studied. However, the probes $(H, J$ and $D)$ all appear to be useful, be it in combination with other PCR assays $(\mathrm{G} / \mathrm{J}$ and $H / K)$. The sensitivity of the assays was in the order of $1 \mathrm{pg}$ of $G$. vaginalis DNA. This should be sufficient for clinical use since in BV G. vaginalis is thought to be present in large numbers.

\section{Species typing in relation with biochemical characteristics and fatty acid analysis}

Phenotypic analysis of twelve $G$. vaginalis isolates and one isolate of a related species were performed by the ID32 strep Microtest and fatty acid analysis. Generally, the fatty acid content of $G$. vaginalis consisted of $40 \%$ palmitate, $33 \%$ oleate, $9 \%$ myristate, $8 \%$ stereate and $3 \%$ palmitoleate. A survey of all results obtained is given in Table 3. For two strains (numbers 11 and 12) the identification results of the biochemical and fatty acid analyses were contradictory. Fatty acid analysis identified the strain as $G$. vaginalis which was confirmed by a positive PCR result. Except for strain 1, all remaining strains that are positive in the fatty acid analysis or the biochemical typing or both are identified as $G$. vaginalis by PCR. One strain with abberant fatty acid profile and another strain with a deviating ID32 strep test were still identified as $G$. vaginalis by PCR (isolates 7 and 9 , respectively). The results for strain 5 , negative biochemistry and abberant fatty acid profile, are corrobarated by a negative PCR result. S. acidominimus remains negative in the PCR test.

The identification of $G$. vaginalis by means of phenotypic tests is known to be troublesome and fatty acid analysis often does not distinguish between closely related organisms. ${ }^{17}$ However, among this limited number of isolates the results of both phenoand genotyping assays show a considerable degree of homology. In eight out of 13 , all results point in the same direction (isolates 2-6, 8, 10 and 13, see
Table 3). For three strains (numbers 9, 11 and 12 in table 3), the ID32 identification is contradictory with PCR and fatty acid analysis. In these cases fatty acid analysis and PCR identify the organism as G. vaginalis, whereas the ID32 test is negative in this respect. For one strain (number 7 , table 3 ), fatty acid analysis is negative whereas PCR and ID32 strep testing identify G. vaginalis.

\section{Perinatal $G$. vaginalis infections}

In the randomized group of gynaecological patients 19 out of 52 women (37\%) carried G. vaginalis. Ten out of $11 \mathrm{BV}$ patients were positive for $G$. vaginalis. This comprises over $90 \%$ of the females in this group. Among the pregnant women, nine out of 20 were colonized with $G$. vaginalis ( $45 \%)$. For a survey of these data, see Table 4. There appears to be no statistically significant difference in prevalence between the control group and the group of pregnant women. Apparently, pregnancy does not predispose to $G$. vaginalis colonization. Children born from $G$. vaginalis-infected females showed an average weight of $3290 \mathrm{~g}$ and gestation lasted 39.2 weeks. For children from the non-colonized females the average weight was $3360 \mathrm{~g}$, duration of gestation was $40 \cdot 1$ weeks. This does not constitute a statistically significant difference.

\section{DISCUSSION}

A sensitive and specific PCR assay has been developed for $G$. vaginalis. DNA sequences within the internal transcribed spacer and 23S rRNA region appeared to be both species specific and well-enough conserved among isolates to allow adequate test design. For several other species sequence variation has been documented in the ITS region ${ }^{21}$ but in $G$. vaginalis, if any variability exists, this does not seem to hamper test results. It has to be mentioned that the most optimal PCR assay (primers $\mathrm{H}$ and $\mathrm{K}$ combined with probe $D$ ) uses sequences from the $23 \mathrm{~S}$ gene exclusively. In this case potential ITS variability is of no diagnostic concern. Since the PCR discriminates between genuine $G$. vaginalis and $G$. vaginalis-like organisms this test could provide additional clues when identity of a given organism is questionable (see Table 3). A recently published study on $G$. vaginalis-like organisms from the reproductive tract of the mare could profit from additional PCR analysis. ${ }^{22}$

$G$. vaginalis has repeatedly been indicated as an organism at least partially responsible for various 

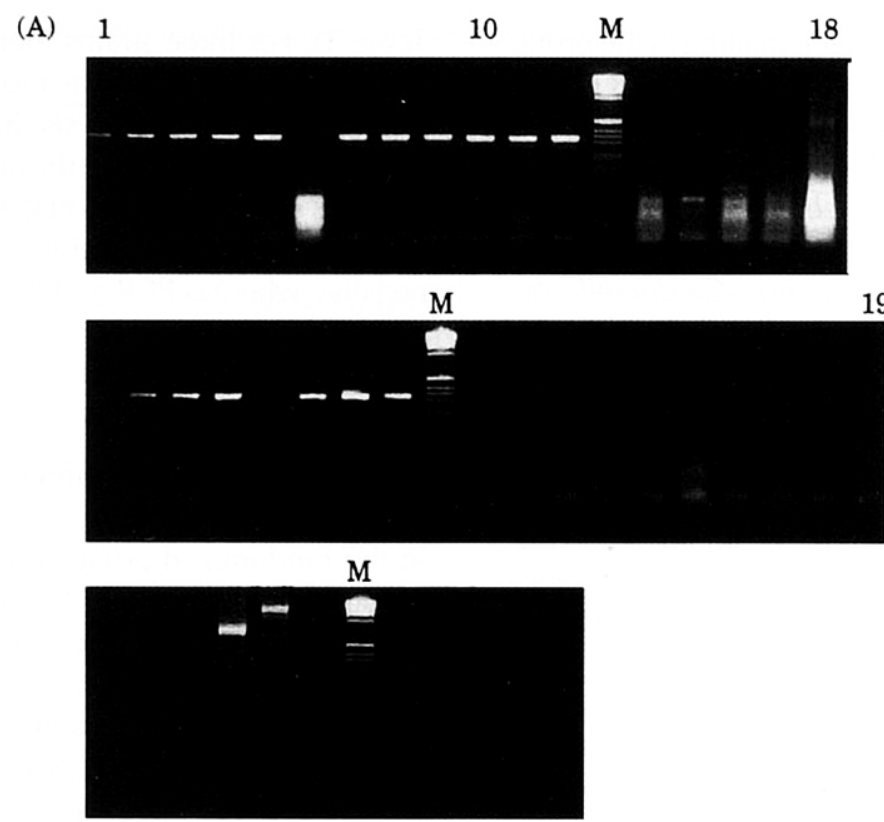

12

(B)

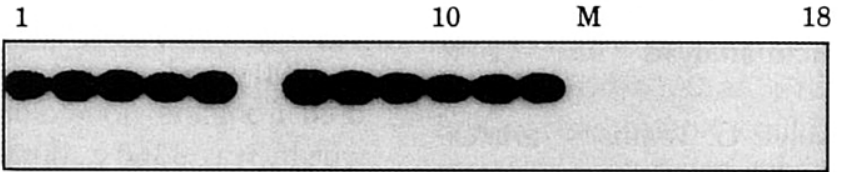

M 19

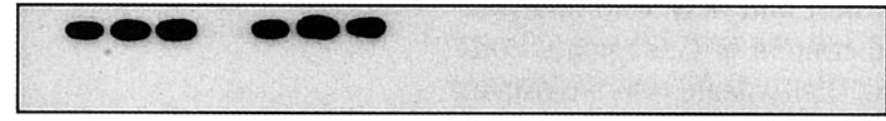

M

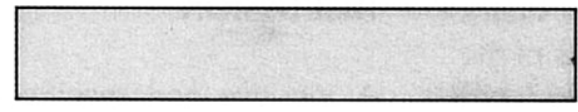

1

12

Fig. 1. (A) Survey of amplimers obtained by PCR mediated amplification of DNA from G. vaginalis, other microorganisms and cervical smears by use of primers $\mathrm{H}$ and $\mathrm{K}$ (see Table 2 for primer sequences). Note that only when $G$. vaginalis DNA is present, is a fragment of the correct length generated, other template DNAs give rise to unspecifically synthesised DNA molecules at best. Lanes marked $M$ contain bacteriophage lambda DNA, digested with the restriction enzyme HindIII, which serves as molecular length marker. The lane numbering corresponds to samples obtained after amplification of DNA from the following materials: Top panel, purified DNA from 1. G. vaginalis CCUG 3717; 2 . G. vaginalis CCUG 3990; 3. G. vaginalis CCUG 4123; 4. G. vaginalis CCUG 7921; 5. G. vaginalis CCUG $11278 A ; 6$. Staphylococcus aureus; 7. G. vaginalis CCUG 28963; 8. G. vaginalis CCUG 30587; 9. G. vaginalis CCUG $30841 ; 10$. G. vaginalis CCUG 7154; 11. G. vaginalis CCUG 7712; 12. G. vaginalis ATCC 14018/11; 13. molecular length marker; 14. Bifidobacterium breve LMG 13208; 15. Bifidobacterium longum LMG 13207; 16. Bifidobacterium magnum LMG 11590; 17. Bifidobacterium bifidum LMG 13209; 18. Bifidobacterium infantis LMG 13203; Middle panel. DNA from cervical smears from women not presenting symptoms (lanes 1 through 8). Lane 9 displays the molecular length marker, lanes 10 through 19 harbour amplified DNA from the following Lactobacillus acidophilus strains: 10. 1719/8; 11. 1834; 12. 1893 ; 13. 2028; 14. 1997; 15. 1919; 16. 2604/5; 17. 2604/8; 18. 3313/16; 19. 5658/19; Bottom panel, amplimers obtained after amplification of $50 \mathrm{ng}$ of purified DNA from the following micro-organisms: 1. Mycoplasma hominis; 2. Escherichia coli; 3. Chlamydia trachomatis; 4. Bacillus subtilis; 5 . Listeria monocytogenes; 6. Enterococcus sp.; 7. molecular length marker; 8. Peptococcus sp.; 9. Streptococcus agalactiae; 10. Salmonella serovar godesberg; 11. Salmonella serovar flexneri. Lane 12 contains the results of a negative control amplification. Instead of DNA only water was added. (B) Hybridization analysis. DNA from the gels shown in (A) was transferred to nylon and the resulting blot was hybridized with probe D (see Table 2). Note that only DNA synthesised with $G$. vaginalis DNA as template shows specific hybridization with the probe (see also Results and Discussion section). 
Table 4. Detection of Gardnerella vaginalis by PCR in cervical smears from diverse groups of women

\begin{tabular}{lrl}
\hline & Present & Absent \\
\hline Random group $(n=52)$ & $19 / 52(37 \%)$ & $33 / 52(63 \%)$ \\
Pregnant women $(n=20)$ & $9 / 20(45 \%)$ & $11 / 20(55 \%)$ \\
BV patients $(n=11)$ & $10 / 11(91 \%)$ & $1 / 11(9 \%)$ \\
\hline
\end{tabular}

The number of women in each group is indicated by $n$, percentages are given between brackets. $\mathrm{BV}$ : bacterial vaginosis.

genital syndromes both in $\operatorname{men}^{23}$ and women. ${ }^{24} \mathrm{Mul}-$ tiple studies on neonatal infection have been performed. ${ }^{25,26}$ In our patient population, the $G$. vaginalis prevalence in non-symptomatic, non-pregnant females is $36 \%$ (19/52 individuals), whereas in pregnant females this percentage amounts to $45 \%$. These percentages exceed the number of carriers $(6 \%)$ as reported before. ${ }^{27}$ However, this latter prevalence was determined by cultivation assays and it may be assumed that the sensitivity of PCR is superior to that of cultivation.

G. vaginalis may be involved in prematurity or growth retardation of the newborn infant. In two previous large studies on the effect of $G$. vaginalis infection on preterm birth, percentages of colonization are low, but both these studies indicate significant differences in degree of colonization in women either giving preterm birth $12 \%$ and $23 \%$, respectively) or giving birth at term (6\% and $15 \%$, respectively). ${ }^{28,29}$ These results are again based on cultivation assays. Data from preliminary studies using PCR as the diagnostic instrument are not yet sufficient to confirm or reject these data (work in progress). It is also reassuring to note that the $G$. vaginalis incidence in patients suffering from bacterial vaginosis is in the order of $90 \%$. Percentages as high as $64-79 \%$ and diagnosed by cultivation have been reported. ${ }^{30}$

More extensive studies employing PCR diagnosis of $G$. vaginalis and other BV related micro-organisms are required, whereas also quantification of the actual number of $G$. vaginalis bacteria present may have clinical implications. ${ }^{31} \mathrm{~A}$ technical problem is posed by the fact that PCR, fatty acid analysis and biochemical determination sometimes show contradictory results. If the clinical relevance of $G$. vaginalis infection is to be established, additional evaluation of diagnostic procedures is still required.

\section{ACKNOWLEDGEMENTS}

We thank Henny Dekker (SSDZ, Delft, The Netherlands) for technical assistance and Dr E. M. Veringa (Diaconessenhuis, Leiden, The Netherlands) is acknowledged for microbiological advice. Dr B. Pot (Laboratorium voor
Microbiobiologie, Gent, Belgium) is acknowledged for providing the Bifidobacterium species. Dr R. Rossau (Innogenetics, Zwijnaarde, Belgium) suggested the use of ribosomal consensus primers. P. Vandamme is indebted to the National Fund for Scientific Research (Belgium) for a post-doctoral research fellowship.

\section{REFERENCES}

1. Spiegel, C. A. (1991). Bacterial vaginosis. Clinical Microbiology Reviews 4, 485-502.

2. Balsdon, M. J., Taylor, G. E., Pead, L. \& Maskill, R. (1980). Corynebacterium vaginale and vaginitis: a controlled trial of treatment. Lancet $i, 501-4$.

3. Piot, P., van Dijck, E., Goodfellow, M. \& Falkow, S. (1980). A taxonomic study of Gardnerella vaginalis (Haemophilus vaginalis) Gardner and Dukes 1955. Journal of General Microbiology 119, 373-96.

4. Koutsky, L. A., Stamm, W. E., Brunham, R. C., Stevens, C. E., Cole, B., Hale, J., Davick, P. \& Holmes, K. K. (1983). Persistence of Mycoplasma hominis after therapy: importance of tetracycline resistance and of coexisting vaginal flora. Sexually Transmitted Diseases 11 (Suppl), 374-81.

5. Spiegel, C. A., Amsel, R., Eschenbach, D., Schoenknecht, F. \& Holmes, K. K. (1980). Anaerobic bacteria in nonspecific vaginitis. New England Journal of Medicine 303, 601-7.

6. Blackwell, A. L., Fix, A. R., Phillips, l., Barlow, D. (1983). Anaerobic vaginosis (non-specific vaginitis): clinical, microbiological and therapeutic findings. Lancet ii, 1379-82.

7. Spiegel, C. A. (1989). Gardnerella vaginalis. In Principles and Practice of Infectious Diseases (Mandell, G. L., Douglas, R. G. and Bennett, J. E. eds). 3rd edn, New York: Churchill Livingstone.

8. Eschenbach, D. A., Buchanan, T. M. \& Pollock, H. M. (1973). Polymicrobial etiology of acute pelvic inflammatory disease. New England Journal of Medicine 293, 166-72.

9: Watts, D. H., Eschenbach, D. A. \& Kenney, G. E. (1989). Early postpartum endometritis: the role of bacteria, genital mycoplasmas and Chlamydia trachomitis. $\mathrm{Ob}$ stetrics and Gynecology 73, 52-60.

10. Hooton, T. M., Finn, S. D., Johnson, C., Roberts, P. L. \& Stamm, W. E. (1989). Association between bacterial vaginosis and acute cystitis in women using diaphragms. Annals of Internal Medicine 149, 1932-6.

11. Piot, P., van Dijck, E., Totten, P. A. \& Holmes, K. K. (1982). Identification of Gardnerella (Haemophilus) vaginalis. Journal of Clinical Microbiology 15, 19-24.

12. Bratos, M. A., Orduna, A., Medina, J., de Lejarazu, J. O. \& Rodriguez-Torres, A. (1986). Diagnosis of Gardnerella vaginalis infection by an enzyme linked immunosorbent assay. European Journal of Clinical Microbiology and Infectious Diseases 5, 46-8.

13. Hansen, W., Kray, B., Miller, K., Crokaert, F. \& Yourassowsky, E. (1987). Detection of Gardnerella vaginalis in vaginal specimens by direct immunofluorescence. Journal of Clinical Microbiology 25, 1934-7.

14. Nath, K., Chooi, D. J., Develin, D. (1991). The characterisation of Gardnerella vaginalis DNA using nonradioactive DNA probes. Research in Microbiology 142, 573-83. 
15. Pao, C. C., Lin, S. S. \& Hsiek, T. T. (1990). The detection of Gardnerella vaginalis DNA sequence in uncultured clinical specimens with cloned $G$. vaginalis DNA as probes. Molecular and Cellular Probes 4, 367-73.

16. Sheiness, D., Dix K., Watanabe, S. \& Hillier, S. L. (1992). High levels of Gardnerella vaginalis detected with an oligonucleotide probe combined with elevated $\mathrm{pH}$ as a diagnostic indicator of bacterial vaginosis. Journal of Clinical Microbiology 31, 642-8.

17. Vandamme, P., Vancanneyt, M. \& Pot, B. (1992). Polyphasic taxonomic study of the emended genus Arcobacter with Arcobacter butzleri comb. nov. and Arcobacter skirrowii sp. nov., an aerotolerant bacterium isolated from veterinary specimens. International Journal of Systematic Bacteriology 42, 344-56.

18. Olson, G. J., Larsen, N. \& Woese, C. R. (1991). The ribosomal RNA database project. Nucleic Acids Research 19, 2017-21.

19. Jannes, G., van Eechoulte, M. \& Lannoo, M. (1993). Polyphasic taxonomy leading to the proposal of Moraxella canis sp. nov. for Moraxella catarrhalis-like strains. International Journal of Systematic Bacteriology 43, 438-49.

20. Melchers, W. J. G., Schift, R., Stolz, E., Lindeman, J. \& Quint, W. G. V. (1989). Human papillomavirus detection in urine samples from male patients by the polymerase chain reaction. Journal of Clinical Microbiology 27, 1711-14.

21. Bacot, C. M. \& Reeves, R. H. (1991). Novel tRNA gene organization in the 16S-23S intergenic spacer of the Streptococcus pneumoniae rRNA gene cluster. Journal of Bacteriology 173, 4234-36.

22. Salmon, S. A., Walker, R. D., Carleton, C. L., Shah, S. \& Robinson, B. E. (1991). Characterisation of G. vaginalis and $G$. vaginalis-like organisms from the re- productive tract of the mare. Journal of Clinical Microbiology 29, 1157-61.

23. Smith, S. M., Ogbara, T. \& Eng, R. H. K. (1992). Involvement of Gardnerella vaginalis in urinary tract infection in men. Journal of Clinical Microbiology 30, 1575-7.

24. Lee, W., Phillips, L. E., Carpenter, R. J., Markus, M. G. \& Faro, S. (1987). Gardnerella vaginalis chorioamnionitis: a report of two cases and a review of the pathogenic role of $G$. vaginalis in obstetrics. Diagnostic Microbiology and Infectious Diseases 8, 107-11.

25. Carney, F. E. (1973). Haemophilus vaginalis septicemia. Obstetrics and Gynecology 41, 78-9.

26. Furman, L. M. (1988). Neonatal Gardnerella vaginalis infection. Pediatric Infectious Disease Journal 7, 890.

27. Saini, S., Sabharwal, U., Chaudhary, M. \& Chaudhary, U. (1992). Vaginitis in non-pregnant women in Haryana. Indian Journal of Pathology and Microbiology 35(2), 125-8.

28. McDonald, H. M., O'Loughlin, J. A., Jolley, P., Vigneswaran, R. \& McDonald, P. J. (1991). Vaginal infection and preterm labour. British Journal of Obstetrics and Gynaecology 98, 427-35.

29. McDonald, H. M., O'Loughlin, J. A., Jolley, P., Vigneswaran, R. \& McDonald, P. J. (1992). Prenatal microbiological risk factors associated with preterm birth. British Journal of Obstetrics and Gynaecology 99(3), 190-6.

30. Deodhar, L. P. \& Pandit, D. V. (1992). Mycoplasma hominis in women with bacterial vaginosis. Indian Journal for Medical Research 95, 144-7.

31. Holst, E., Rossel, Goffeng A. \& Andersch, B. (1994). Bacterial vaginosis and vaginal microorganisms in idiopathic premature labour and association with pregnancy outcome. Journal of Clinical Microbiology 32, 176-86. 